\title{
SANITARY BEHAVIOR BY THE SOCIAL SPIDER MALLOS GREGALIS (DICTYNIDAE): DISTRIBUTION OF EXCRETA AS RELATED TO WEB DENSITY AND ANIMAL MOVEMENTS.*
}

\author{
By William J. Tietjen \\ Department of Biology \\ Georgia College \\ Milledgeville, Ga 31061
}

\section{INTRODUCTION}

The organization of colony behavior by gregarious animals depends not only on the behavioral repertoire observed in individuals but also on physiological limitations evolution has imposed on the species. Such physiological restraints extend to the elimination of metabolic wastes by individuals which can affect the distribution of nutrients and parasites in the immediate environment (McBride, 1976). These by-products, in addition to prey remains, can have important consequences related to nest sanitation in social units of low vagility. In addition, metabolic wastes may perform a secondary communicative function in some species (Tietjen and Rovner, 1981).

Mallos gregalis Simon is one such group-living species of spiders in which thousands of individuals of both sexes and various age groups occupy a semi-permanent web (Burgess, 1976; Diguet, 1908, 1915). To avoid fouling of such a long-term web site, one might expect sanitary behavior in such species. Unlike Agelena consociata, however, which exhibit nest-cleaning behavior by removing prey remains from the web (Krafft, 1969), M. gregalis do not remove carcasses, but incorporate prey remains into the nest structure (Jackson, 1978). Tietjen (1981) suggested that M. gregalis did not foul the web with fecal material, but eliminated wastes near the edge of the web. This produced a ring of excreta which surrounded the web site. These conclusions were, however, based upon observational, rather than experimental data. An alternative explanation can explain the observed ring of excreta: If $M$. gregalis utilize mainly the upper surface of the web they may deposit excreta uniformly over the web surface. If the excreta are incorporated into the web structure as are prey

*Manuscript received by the editor September 8, 1980. 
remains, then one would expect a similar ring of excreta to surround the web site in the laboratory.

The present study quantitatively investigates the distribution of excreta as related to web structure and the distribution of spiders within experimental colonies in order to determine the possibility of systematic sanitary behavior in this species. The effects of group size and available building space on excreta distribution are also described. In addition, methodologies utilizing a computer-camera apparatus for data collection are presented.

\section{Methods}

\section{General Methods}

M. gregalis from a colony collected by G. W. Uetz near Mexico City, Mexico in 1979, was maintained in a climate-controlled room ( $\mathrm{T}=25 \pm 5^{\circ} \mathrm{C}, \mathrm{RH}=90 \pm 10 \%$, natural photoperiod). Animals were daily given a fine spray of water on the surface of the web and were fed houseflies (Musca domestica) at weekly intervals.

One week prior to data collection, about 200 individuals were removed from the above colony; divided into approximatly equalsized groups; transferred to four glass containers $(13 \mathrm{~cm}$ dia, $17 \mathrm{~cm}$ height) and allowed to build webs. On the fifth day each group was fed 10 flies and two days later the colonies were split into samples for experimental analysis. Three group sizes $(\mathrm{N}=5,10$ or 20 adult females) were released into two different-sized petri dishes (large $=96$. $1 \mathrm{cc}$, small $=52.2 \mathrm{cc})$. Each group was allowed a two-week period $(28$ May-11 June 1980) to build a web. During this time they were not fed, but were watered daily by putting droplets of water near the edge of the petri dish. Photoperiod was natural for this summer time of year in North Carolina and temperature was $26.3 \pm 1.1^{\circ} \mathrm{C}$.

II Recording Methods.

Detailed recording methodologies will be presented elsewhere (Tietjen, in prep.) or are available from the author. In brief, a solidstate television camera (Perificon type 511 image digitizer) was connected to a CDP-1802 microprocessor-based computer via a suitable interface. The computer acted as an "intellegent controller" of the camera and, through appropriate software (see below), could regulate the exposure time, number of frames per sec and the formating of data. Data were stored in computer memory during collection and were transferred to magnetic tape for future analyses.

The camera provided a potential matrix array of $32 \times 32$ picture 
elements ( $=1024$ pixels); however, a mask which simplified position analysis reduced the actual number of elements used in statistical analyses to $502 \pm 10$ pixels for the small and $571 \pm 16$ pixels for the large petri dish (Fig. 1). The camera was located $.65 \mathrm{~m}$ from the recording surface providing a field of view for each pixel of $3.8 \mathrm{~mm}^{2}$ (about the size of a mature female $M$. gregalis).

The density of silk at each of the 1024 positions within the container was recorded by programming the computer to begin at a short exposure time (13ms) and record in computer memory the positions of those pixels activated by light. The exposure time was then increased in $.03 \mathrm{~ms}$ increments 1024 times. Each iteration resulted in darker areas in the field of view being recorded. This resulted in a grey-level representation of the image in 1024 levels at each of the positions. Because silk blocked out light, grey-level and silk density were inversely proportional.

To compensate for possible uneven lighting effects and to scale the data to silk-density at each point, the above data were subtracted from base-level information obtained by taking a grey-level picture in

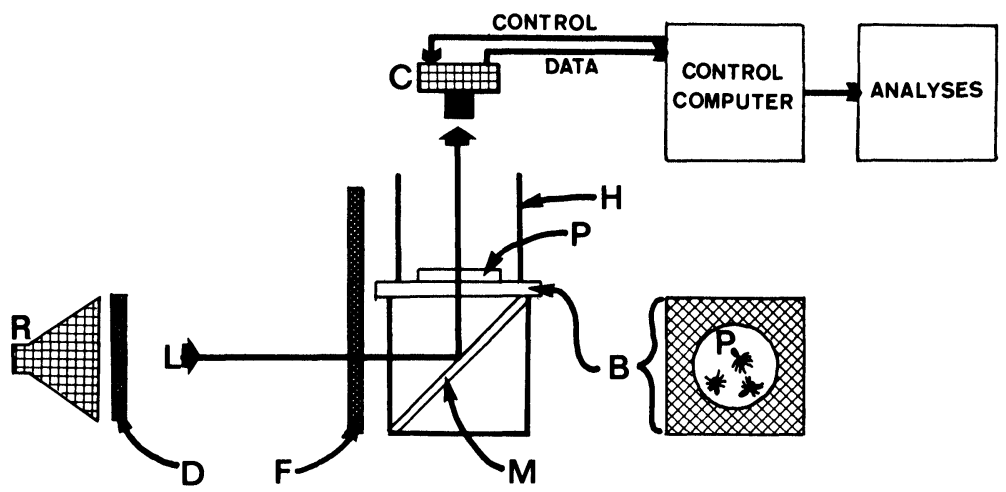

Figure 1: Computer-controlled camera equipment designed to record the distributions of animals and excreta as related to silk densities. Transmitted light (L) is provided by a light source and a refector $(R)$ with a diffusion screen (D). Light passes through a transparent red plastic filter $(F)$ and is reflected by an opaque white plastic mirror (M) which provides for further diffusion of the light. The light passes through a clear plastic base (B) and into a petri dish (P) which holds the experimental colony. An opaque mask blocks light outside the colony recording area and a hood (H) surrounding the recording area reduces the ambient light level seen by the camera (C). The camera is controlled by a computer which also receives the image data. This information is transmitted to a second computer for numerical analyses. 
the absence of the spiders, excreta and web (e.g. just the base and petri dishes for each colony). Thus $S_{i}=B_{i}-G_{i}$ where $S_{i}$ is the silkdensity of the $i^{\text {th }}$ element in the array; $B_{i}$ is the base-level data and $\mathrm{G}_{\mathrm{i}}$ is the grey-level data which included the colony. The more than 2.0 $\times 10^{6}$ calculations required to construct the grey-level image took about $3 \mathrm{~min}$ of computer time. As it was not possible to remove the spiders without damaging the web and distribution of the silk, the spiders had to be killed prior to data collection since their movements would cause changes in the image. Following silk-density data collection, the positions of animals and excreta were recorded with the camera and the aid of a light pen. The silk-density data at these elements were affected by the presence of the animals or feces and were later adjusted to the average of the eight surrounding pixels for final analyses.

In another experimental series, to record the position preferences of animals throughout the night, the computer took a picture in an intervalometer mode ( 1 frame per $3 \mathrm{sec}$ ), recording in computer memory those positions currently occupied by spiders $(273724$ frames total). Two colonies located in the small petri dishes were recorded for a five-day period (1600-0900; 5 animals per colony). The resulting data represented the amount of time each element of the array was occupied by an animal. This provided an estimate of the "attractiveness" of each position since favorable positions would be expected to have spiders occupying them for a greater amount of time than unattractive positions. Following collection of these data, I took a grey-level picture of the colony to record the approximate distribution of silk-density within the petri dish. All light received by the camera was transmitted through the colony. Transmitted light was provided by an incandecent bulb located in a reflector fitted with a diffusion screen. The light source was located $1.0 \mathrm{~m}$ from the recording apparatus. Before the light was passed through the colony, it was reflected off a white plastic "mirror" to provide for further diffusion of the light. When collecting silk-density data I used a 200 W bulb. In order to record normal night activity, a $60 \mathrm{~W}$ bulb was used in conjunction with a red filter and a hood to record the positions of living animals throughout the night (Fig. 1). The addition of the filter and hood reduced the light to the point where I could no longer recognize the positions of the animals with the unaided eye. The reduced light intensity did not affect camera operation because the camera's peak sensitivity is in red light. 
Following data collection, the information saved on tape was loaded back into the CDP-1802 computer and formated for analysis. Although the CDP-1802 computer is well suited as an intelligent controller, it is laborious to program statistical analyses in such a system. For this reason, the formated data were transmitted to another computer for numerical analyses (Ohio Scientific C1P). Statistical analyses were performed according to the methods of Conover (1971) and Sokal and Rohlf (1969). All means are accompanied by their standard deviations.

\section{RESULTS}

The distribution of silk in all colonies was clumped with variance to mean ratios ranging from 79.4 to 126.0 (Chi-Square test $\mathrm{p}<.001$; Table 1). Examination of the data indicated that nearly all of the silk was deposited near the periphery of the container with little or no silk deposited in the central area (Fig. 2,3). The edge of the petri dishes contained numerous chambers and tunnels common to typical $M$. gregalis webs (Burgess, 1976). Most silk appeared to be dragline rather than cribellate silk.

\section{TABLE 1}

Intermediate results for the number of animals, silk density and number of excreta for colonies of Mallos gregalis reared in containers of two sizes. The variance to mean ratios indicate considerable clumping of silk within all colonies (Chi-square test, $\mathrm{p}<.001)$. Silk density is expressed in arbitrary units related to the amount of light received by the camera.

$\begin{array}{lccccc}\text { Size } & \begin{array}{c}\text { Number of } \\ \text { Animals }\end{array} & \begin{array}{c}\text { Number of } \\ \text { Pixels }\end{array} & \begin{array}{c}\text { Mean Silk } \\ \text { Density }\end{array} & \begin{array}{c}\text { Variance to } \\ \text { Mean Ratio } \\ \text { for Silk }\end{array} & \begin{array}{c}\text { Number of } \\ \text { Excreta per } \\ \text { Colony }\end{array} \\ \text { small } & 5 & 511 & 257.1 \pm 148 & 85.2 & 16 \\ & 5 & 487 & 226.5 \pm 140 & 86.5 & 10 \\ & 5 & 510 & 272.7 \pm 198 & 88.6 & 13 \\ & 20 & 503 & 312.1 \pm 198 & 126.0 & 43 \\ \text { large } & 20 & 500 & 363.3 \pm 170 & 79.4 & 34 \\ & 5 & 582 & 255.9 \pm 151 & 89.2 & 12 \\ & 5 & 588 & 273.6 \pm 154 & 86.6 & 30 \\ & 10 & 555 & 265.2 \pm 148 & 82.4 & 27 \\ & 10 & 576 & 284.1 \pm 161 & 91.8 & 31 \\ & 20 & 554 & 322.6 \pm 194 & 116.9 & 30\end{array}$


The mean number of sampled elements in the small container was

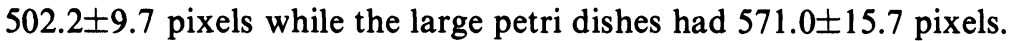
Within-group (e.g. large or small container) variation for number of elements did not show a significant difference (small: $\chi^{2}=0.75$, ns; large $\chi^{2}=1.72$, ns) while considerable between-group variation was seen (Mann-Whitney test, $\mathrm{T}=0.0, \mathrm{p}<.001)$. Repeated pictures of the same colony indicated that within-colony variation was low $(0.95 \%)$. The small amount of within-group (large or small containers) and within-colony variation was due to the difficulties in representing a circular image with an array composed of square elements. The between-group variation was due to the different sizes of the containers.

Most excreta located on the surface of the container were circular although a few irregular forms were seen. Margins were either smooth or undulate and color ranged from dark ebony to light tan; often with the central area being darker than the surrounding margin. The mean diameter was $1.1 \pm 0.4 \mathrm{~mm}(\mathrm{~N}=70$; irregular forms were not measured) and there was no evidence of mold or bacterial growth (measured with a $10 \times$ micrometer).

In contrast to the above, it was very difficult to measure the dimensions of excreta deposited on silk as such material tended to flow along the silk line or adhere to adjacent threads. These excreta were whitish to tan in color and had a cracked appearance under 10X magnification. No mold or bacterial growth was seen.

It was not possible because of the varied form and color of the excreta to quantify the amount of material at each deposition site by optical means. For this reason only the presence or absence of excreta was analyzed. To investigate the distribution of excreta as related to silk distribution, the silk density data were divided into ten levels $(0-99,100-199 \ldots 900-1000$ density units). No silk density data were greater than 1000 density units. This was necessary because of the relatively low number of fecal deposits in each container $(\bar{Y}=24.6 \pm 11.0$; Table 1; Fig.2). Analyzing each colony individually, a positive correlation was observed between the number of pixels within each of the ten silk-density ranges and the number of excreta (Spearman's rho, $\rho=+0.93, \mathrm{p}<.01$ ). In addition, examination of the data indicated similar distributions of excreta, animals and silk densities both between container sizes and among colony sizes. The data were therefore pooled for further analyses and a positive 

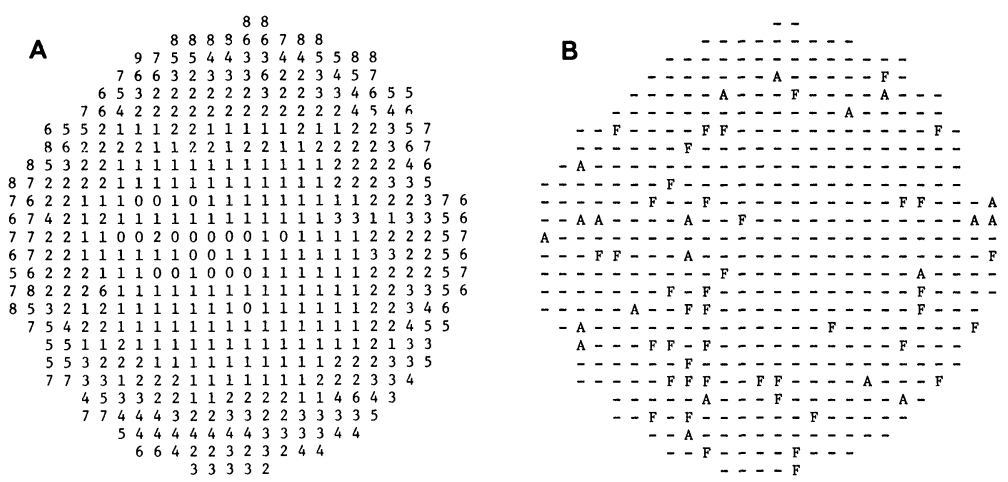

Figure 2: Representative silk-density image (A) and distribution data for animal and excreta positions (F). Silk-density data have been adjusted to a ten-level ordinal scale with 9 representing the highest observed silk densities. Note that the most dense silk is found mainly at the outer edge of the container. Figure 2B shows the distribution of fecal material (F) and the dead animals' last positions (A). Data matrices such as these were used in the Model 1 and Model 2 analyses.

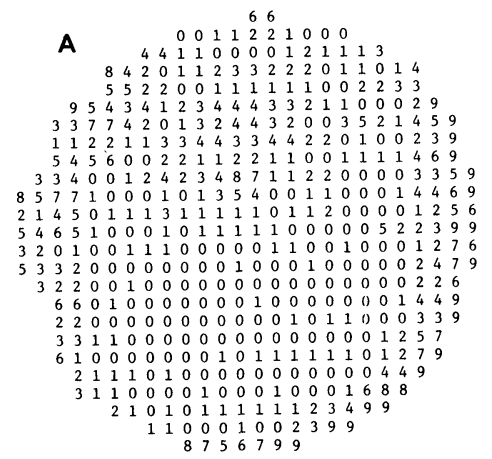

Figure 3: Representative silk density data (A) and live animal frequency distribution data (B). The silk-density scale is linear and is presented as in Fig. 2A. The animal distribution data have been transformed by $\log _{e}$ to indicate that animals did exhibit some short-time presence in the central (low silk density) area. Data such as these were used in the Model 3 approximation. 
correlation was observed between the amount of silk in each of the ten ranges and fecal deposition (Spearman's rho, $\rho=0.71, \mathrm{p}<.025$; Fig. 2,3). These data suggest that excreta were relatively evenly distributed throughout the container. Comparing the observed distribution of fecal material with the expected based on silk density, however, resulted in a significant deviation with too few excreta found at the extreme ranges $\left(\chi^{2}=20.7, p<.02\right.$; Fig. 4). The distribution of excreta as related to the silk-density distribution is referred to as my "Model 1 approximation".

In a similar manner, the distribution of the spiders' last positions (dead animals) was analyzed. These data indicated a clumped distribution as related to silk density $\left(\chi^{2}=106.0, p<.001\right)$ with the lower silk densities exhibiting too few spiders and the high-density silk locations, an excess number of spiders. When the expected distribution of excreta was adjusted to the observed distribution of the animals' last positions, too few excreta were found at the highdensity areas and an excess was found at low-density areas $\left(\chi^{2}=249.2, \mathrm{p}<.001 ;\right.$ Fig 4$)$. These data suggest that animals eliminated wastes outside their most frequent occupation areas and are referred to as the "Model 2 approximation" in following sections.

The data related to the animals' last positions may not provide an accurate model of animal distribution over time as the distribution of these animals may have been affected by the killing process (e.g. animals may have abandoned their normal living areas during refrigeration). Such distributions (Fig. 2) were not typical of those observed in living colonies, as these colonies usually had a majority of the animals located in the periphery areas of the container. Figure 3 shows the distribution of living animals over time. Note that the scale is not linear but that the data have been transformed to $\log _{e}\left(X_{i}\right.$ Without such a transformation, the entire central area and much of the periphery would show zero occupation. Nonetheless, animals were recorded as occupying matrix elements in the periphery of the container for the majority of the time and a positive correlation was observed between the time each position was occupied and that position's silk density (Pearson's $\mathrm{r}, \mathrm{r}=+0.53, \mathrm{p}<.001$ ). Such a distribution of animals was expected based on casual observations of spiders in a variety of containers including petri dishes. These data suggest that the distribution of live animals was more contagious than might be expected from the above results based on the animals' last position. When the expected distribution of excreta was adjusted 
to the model based on the distribution of living animals over time, a significant deviation was observed $\left(\chi^{2}=5960.3, \quad \mathrm{p}<.001\right)$, as approximately $86 \%$ of the fecal material would be expected to be found in the areas of highest silk density (Fig. 4). These data are referred to as the "Model 3 approximation" of expected excreta distribution.

Although the mean silk density of the small vs. the large containers did not differ (small: $(\bar{Y}=286.5 \pm 170.2$ units; large : $(\bar{Y}=280.0 \pm 163.9$ units; Man-Whitney test, $\mathrm{T}=13$, ns), a positive correlation was observed between the number of animals in each colony and the observed mean silk density (Spearman's rho, $\rho=+0.84, \mathrm{p}<.001$; Kruskal-Wallis test, $\mathrm{T}=6.41, \mathrm{p}<.05$ ). Similarly, an animal-number effect was observed for the number of excreta (Spearman's rho, $\rho=+$ $0.82, \mathrm{p}<.005)$. Therefore, an increased number of animals deposit both more silk and more fecal material (Table 1); however, these results do not affect the above analyses as the distribution of excreta, animals and silk did not differ among colonies of varying size or between container sizes.

\section{Discussion}

\section{Evaluation of Methodology}

The apparatus cannot recognize structural features of the web (e.g. chambers and tunnels) but instead describes the web as a series of points having differing silk densities. As such structures tend to be enveloped in dense silk, however, the data do reflect the relative complexity of one area over another. Using methods similar to those used to record excreta positions, one could record the distribution of structural features within colonies.

The testing of the colonies in a relatively confined space has both advantages and disadvantages. An obvious objection is related to the "unnaturalness" of the laboratory situation. In the field, however, as the animals roll leaves to support the web structure, one might expect the construction of similar confined spaces. A decided advantage of confinement is a reduction in web-shape variability among colonies thus allowing detailed statistical analyses with reasonable sample sizes. Such webs, although built in a confined space, are typical when compared to those built in larger containers. Hollar et al. (in review) indicated that $M$. gregalis prefer to build in the corners of varioussized containers (ranging from small glass vessels to room-sized environments). The utilization of the petri dishes by the spiders in 
these experiments is as would be expected from the above data. Similarly, Witt (personal communication) has indicated that $M$. gregalis have a propensity to occupy the narrowest available space in various-sized vessels, usually resting at the outermost edge of circular containers and treating this area as the interior of the web. Comparable results were seen in the distributions of animals and the time spent at various positions within the petri dishes. The distributions of animals and varying silk densities in this experiment, when compared to the above data, suggest that $M$. gregalis treat the periphery of the petri dishes as web-interior and the central region as web-exterior.

A third limitation was caused by the electrical response of the photodetectors to intermediate lighting conditions which may result in an erratic output. This problem was especially noticeable at the edge formed by the opaque mask surrounding the colonies. It was not possible to remove the mask as that would increase programming requirements beyond the present system's capabilities. As a partial solution to this problem, the data points representing the outer edge of each colony were ignored in statistical analyses. This reduced the sample size only slightly and any possible bias introduced would have decreased the absolute level of the observed contagious distribution. The solution, therefore, would affect analyses only if the degree of clumping were considerably less pronounced than in these experiments.

A final limitation was the relatively long period of time required to construct a grey-level image of the colony as this necessitated killing the spiders. Modifications to the electronics and computer program have since reduced computation time from just over 3 min to under 5 sec. The five-sec computation time should provide for a reliable greylevel image without requiring that the animals be killed.

The apparatus does provide a means of nondisruptively assaying the shape of such webs and permits automated analysis of relatively large data sets. Such techniques should be applicable to a variety of animal distribution studies which use animals of a similar size to adult female $M$. gregalis and their relationship to environmental structure. In addition, the relatively low cost of such a system (under $\$ 600$ ) should make this technology available to a variety of experimenters. Although in these experiments only transmitted light was used, reflected light (visible or IR) could be utilized if it were sufficiently diffused within the recording area. 


\section{Interpretation of Data}

Among the social insects, nest cleanliness occupies much of the workers' efforts. In the social bees, for example, the hive is kept meticulously clean in a variety of ways: 1) brood cells are cleared of excreta and molted skins; 2 ) adults move to the outside of the hive to eliminate excreta; 3 ) injured larvae and pupae are eaten; 4 ) the dead are transported from the nest and 5) large debris are covered with propolis, thus isolating the foreign object from the nest environment. Such sanitary behavior by the workers retards or eliminates bacterial and fungal growth in the high-humidity environment of the hive (Morse, 1972; Wilson, 1971).

Similar data suggest the existence of sanitary behavior in $M$. gregalis. The first-approximation model (based on the distribution of silk) indicated that excreta were nearly uniformly deposited over the surface of the web in all colonies (Fig. 4). These data suggest that $M$. gregalis exhibit little or no sanitary behavior as related to the deposition of excreta. The second and third-approximation models were based respectively on the animals' last positions and the animals' distribution over time. The latter two models indicated an inverse

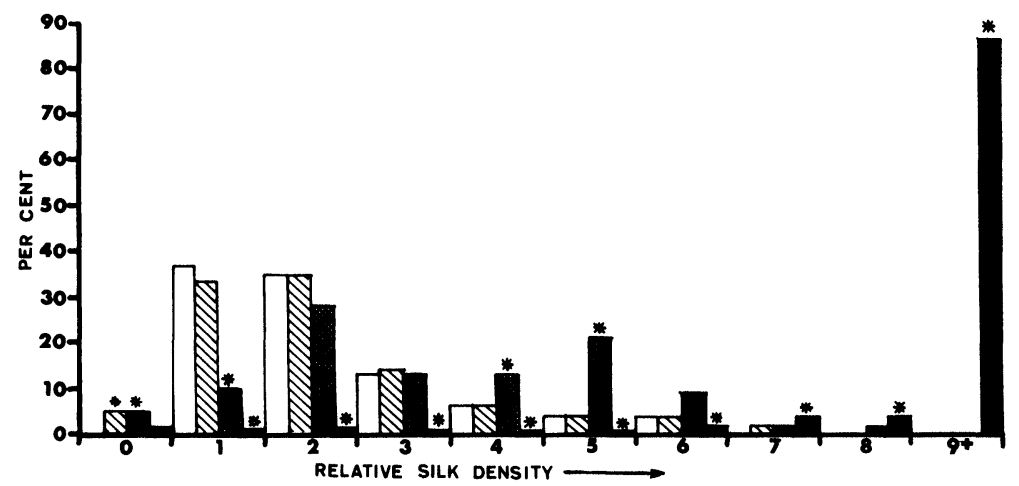

Figure 4: Relative silk densities vs. excreta for the threee excreta distribution models. Silk density increases from zero to nine. Unmarked bars indicate the observed distribution of feces for each relative silk density range. Cross-hatched bars represent the expected distribution based on the absolute quantity of silk within each density range (Model 1). Stippled bars are the expected distribution of excreta based on the animals' last positions (Model 2). The dark bars represent the expected distribution of excreta based on continuous recording of the animals' movements (Model 3). The asterisk-marked bars indicate a significant deviation from the observed excreta distribution (Chi-square test, $\mathrm{p}<.01$ ). 
relationship between the areas occupied by spiders and the site of excreta deposition. These data indicated that spiders typically were associated with high-density silk sites (near the periphery of the containers) and, in contrast to the first model, that they deposit excreta outside their normal area of habitation. Thus, too many excreta were observed in areas of low silk density suggesting that sanitary behavior related to excreta deposition occurs in $M$. gregalis (Fig. 4). The limited amount of time spiders occupied the central area of low silk density (i.e. the outside of the web) suggest that, in part, they moved into this region in order to deposit excreta. Other possible reasons for visiting the central part of the containers include exploratory behavior and possible expansion of the web. Of the three models tested, the third is probably the most accurate as it depends on the actual distribution of living animals. As such, it indicates that animals deposit excreta at sites removed from their areas of occupation (i.e. in the area they treat as web-exterior).

The malpighian tubules of spiders excrete guanine, adenine, hypoxanthine and uric acid into the cloaca with approximatly $34-76 \%$ of the excretory material being guanine (Anderson, 1966). The relative insolubility of these compounds makes it unlikely that the smooth-surfaced excreta deposited on the floor of the chambers could provide potential growth sites for bacterial and fungal colonies. The excreta found on silk, however, were cracked and pitted. Such cracks could provide potential growth sites for colonies in a highhumidity environment; however, under the present conditions no such growth was observed. In a related series of experiments, colonies of various sizes (10-80 individuals) were housed in glass containers (13 cm dia, $17 \mathrm{~cm}$ height; Witt, personal communication). Initially, the majority of spiders inhabited only the upper portions of the vessels. After 4-6 weeks, however, they began to leave the main web and built a separate secondary web in the lower part of the container. Six colonies were available for my examination, all of which had contained spiders for over two months. Fouling of the lower web by excreta was evident on examination of the colonies. In addition, both fly and spider carcasses exhibited evidence of fungal and / or bacterial growth. Dead spiders and prey in the upper portion of the containers typically did not support such growth. Evidently, animals located in the upper section of the containers dropped fecal material onto the lower web. These data suggest that, under certain conditions, bacterial and/or fungal growth is supported by fouling of the nest. In 
nature, however, one would not expect a secondary colony to be formed beneath the primary colony since in the laboratory such associations are rarely seen. The data do indicate, however, that within-colony fouling could occur if $M$. gregalis did not exhibit sanitary behavior.

Excreta produced by $M$. gregalis do not provide chemical messages, as spiders are neither attracted to nor are they repelled from conspecific excreta (Tietjen, unpubl. data). It is possible, however, that excreta could disrupt other modes of communication. A large amount of excreta on the web surface may make adjacent silk threads stick together, possibly affecting the vibration characteristics of the web. Such contamination may directly affect communication among nest mates as suggested by the work of Burgess (1979). Deposition of excreta outside the normal areas of habitation may reduce this potential problem.

Localized excretion sites are, however, only one aspect of sanitary behavior. During the summer months in North Carolina, for example, it is surprising that prey carcasses in the web are not associated with bacterial or fungal growth, as similar organic matter outside the web provides an excellent growth medium for such colonies. Perhaps the venom and/or the digestive fluids of $M$. gregalis serve an additional function analogous to the agents found in honey which discourage bacterial growth (Morse, 1972). In addition to incorporating prey remains into the nest structure, exuviae and dead spiders are often seen in the web matrix. Rarely do the dead spiders exhibit evidence of bacterial or fungal growth and often do these spiders appear as if they have been fed upon (e.g they are dried and shrunken). Jackson (1979) reports two instances of cannibalism in $M$. gregalis and others in this laboratory have observed similar behavior (Hollar and Scarboro, personal communication; Tietjen, unpublished obervation). If only injured or dead individuals are cannibalized (this has not been determined, as cases of cannibalism are very rare) then this behavior may be similar in function to the cannibalistic nest cleaning behavior observed in bees and ants (Wilson, 1971). In a similar vein, I have recorded the distribution of dead spiders within and outside the webs of four colonies confined in glass containers ( $13 \mathrm{~cm}$ dia, $17 \mathrm{~cm}$ height) and found that 14 of the 29 dead spiders were found outside the web area on the bottom surface of the containers. Data presented in this paper (Model 3) would predict that the majority of dead individuals should be associated 
with high-density silk sites (Fig. 3). If this were the case then the dead individuals may have been removed from the web by nestmates or, upon becoming ill, may have left the web on their own as has been described in ants, bees and termites (Wilson, 1971).

I have observed one instance of oophagy by an adult female $M$. gregalis. Upon removing the uneaten eggs from the female, dissecting and examining them under a microscope $(40 \times)$, I found the eggs to be desiccated, suggesting that the eggs were dead before the female began feeding. The consumption of nonliving egg masses would be expected to remove what would have been excellent growth media for bacteria, and similar behavior has been observed in bees and ants (Wilson, 1971).

The rarity of the aforementioned events makes it unlikely that such behavior could be examined quantitatively. Possibly, many of the above behaviors are more prevalant at night when these animals are more active (Tietjen, 1981). Under such viewing conditions, it would be difficult to record cannibalism in $M$. gregalis. However, these data, in conjunction with the quantitative data presented in this paper, suggest that nest-cleaning and other related behaviors do occur in M. gregalis.

Acknowledgements. I am grateful to Dr. P. N. Witt for many helpful discussions during the course of this research and the preparation of the manuscript. The research was supported by National Science Foundation grant BNS 75-09915 to P. N. Witt and W. J. Tietjen, and was conducted in the laboratories of the North Carolina Department of Mental Health.

\section{Literature Cited}

ANDERSON, J. W.

1966. The excreta of spiders. Comp. Biochem. Physiol. 17: 973-982.

BURGESS, J. W.

1976. Social spiders. Scient. Am. 234: 100-106.

1979. Web-signal processing for tolerance and group predation in the social spider Mallos gregalis Simon. Anim. Behav. 27: 157-164.

Conover, W. J.

1971. Practical Nonparametric Statistics. New York: John Wiley and Sons, Inc. $492 \mathrm{pp}$.

DigueT, L.

1908. Sur l'araignée mosquero. Comptes Rendu Acad. Sci. 148: 735-736.

1915. Novelles observations sur le mosquero ou nid d' araignées sociales. Bull. Soc. Nat. Acclim. Fr. 62: 240-249. 
Hollar, W. D., P. N. Witt, M. B. Scarboro and D. B. Peakall

1980. Aggregation: an adaptive stategy in Mallos gregalis Simon (Araneae, Dictynidae). (in review).

JACKSON, R. R.

1978. Comparative studies of Dictyna and Mallos (Araneae, Dictynidae) I, Social organization and web characteristics. Rev. Arachnol. 1: 133-164.

1979. Comparative studies of Dictyna and Mallos (Araneae, Dictynidae) II: The relationship between courtship, mating, aggression and cannibalism in species with differing types of social organization. Rev. Arachnol. 2:103-132.

KRAFFT, B.

1969. Various aspects of the biology of Agelena consociata Denis when bred in the laboratory. Am. Zoologist. 9: 201-210.

MCBRIDE, G.

1976. The study of social organizations. Behaviour. 59: 96-115.

MORSE, R.A.

1972. Environmental control in the beehive. Sci. Am. 226: 92-98.

SOKAL, R. R. AND F. J. ROHLF

1969. Biometry. San Francisco: W. H. Freeman. 776 pp.

TIETJEN, W.J.

1981. Social organization in the spider Mallos gregalis Simon : Individual activity patterns and web-related effects. (in press).

Image digitization techniques for the CDP 1802 microprocessor. (in prep.).

TIETJEN, W.J. AND J. S. Rovner.

1981. Chemical communication in lycosids and other spiders. In: P.N.Witt and J.S.Rovner (Ed.) Spider Communication: Mechanisms and Ecological WILSON, E.O. Significance. Princeton: Princeton University Press. (in press).

1971. The Insect Societies. Cambridge: Belknap. 548pp. 

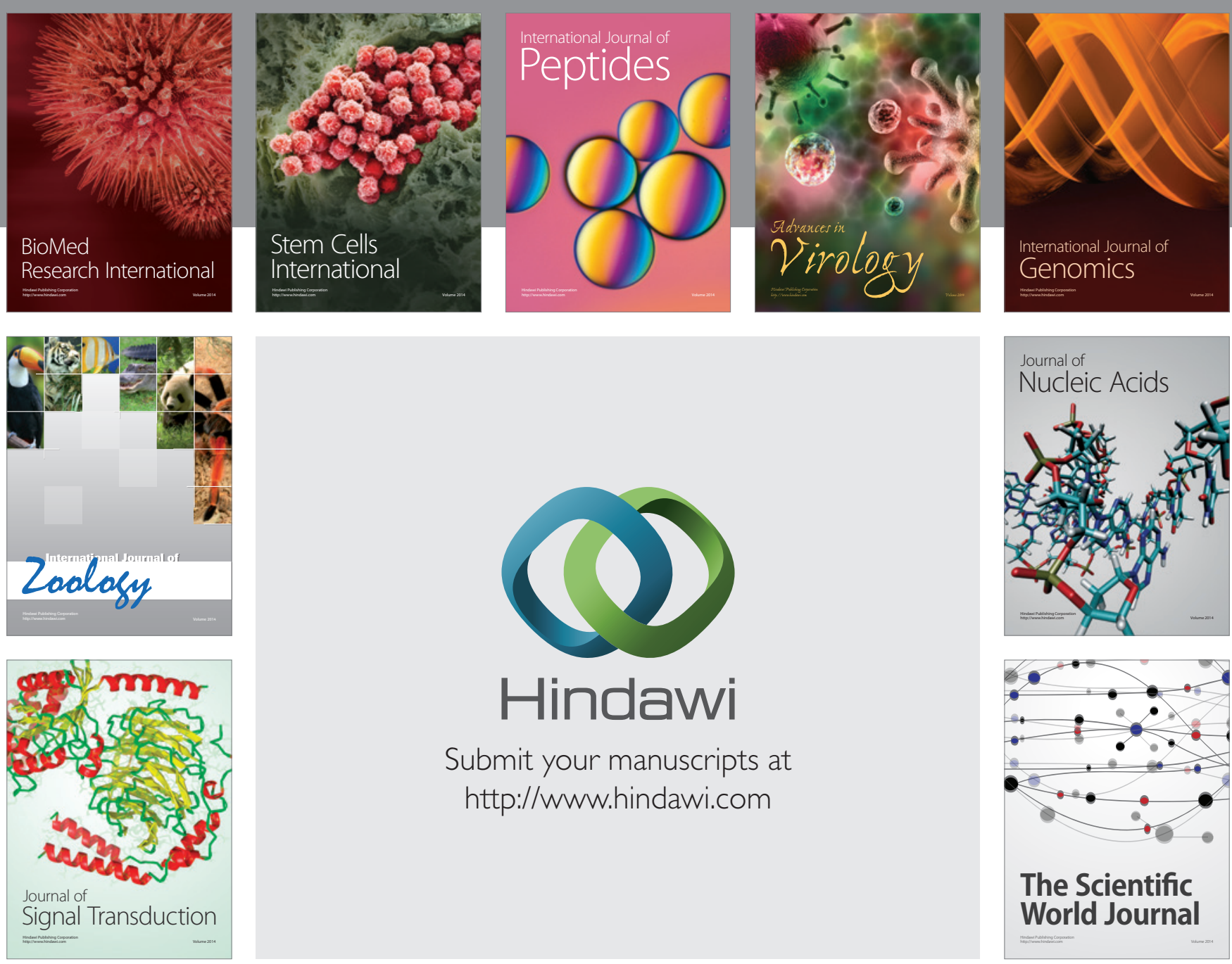

Submit your manuscripts at

http://www.hindawi.com
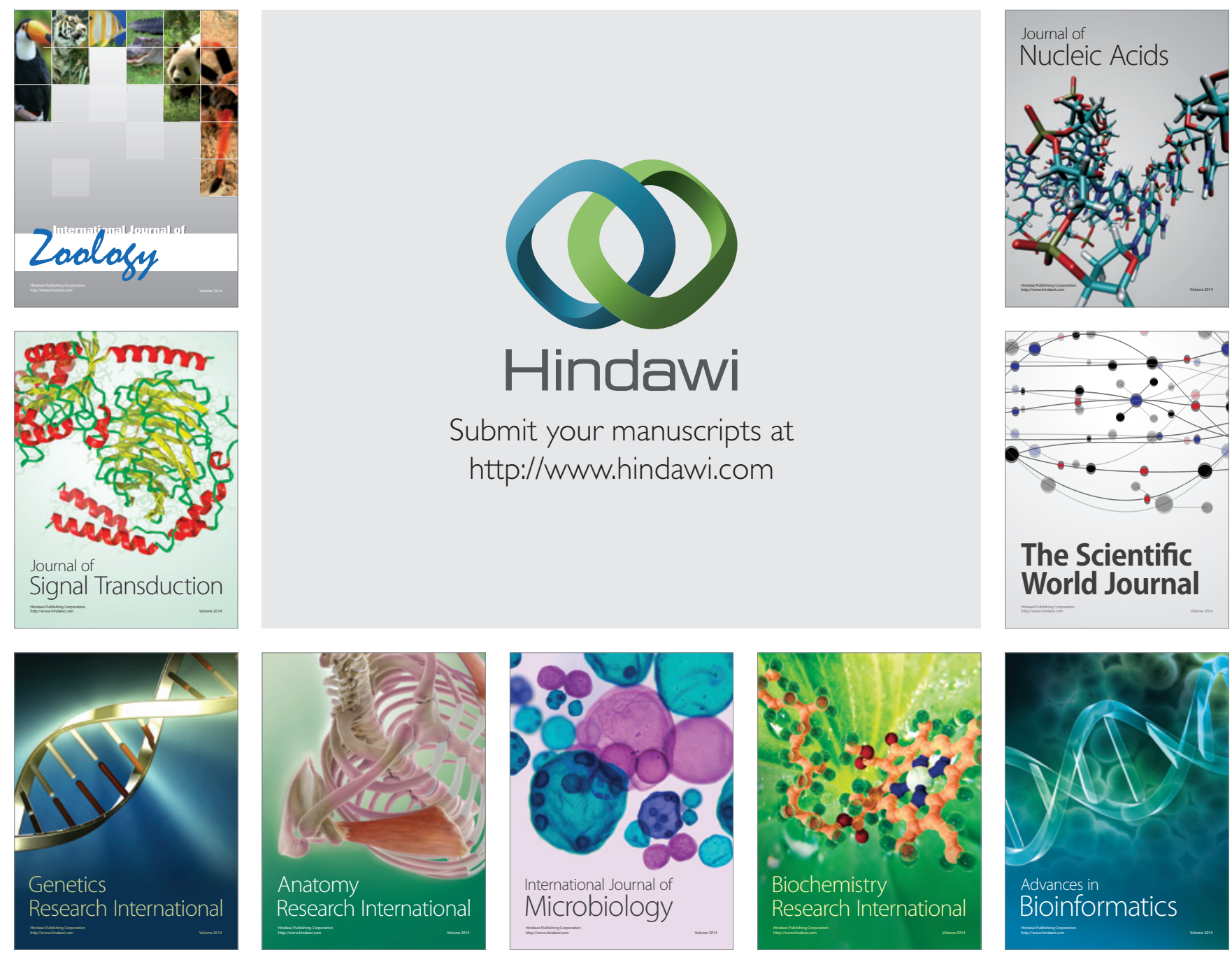

The Scientific World Journal
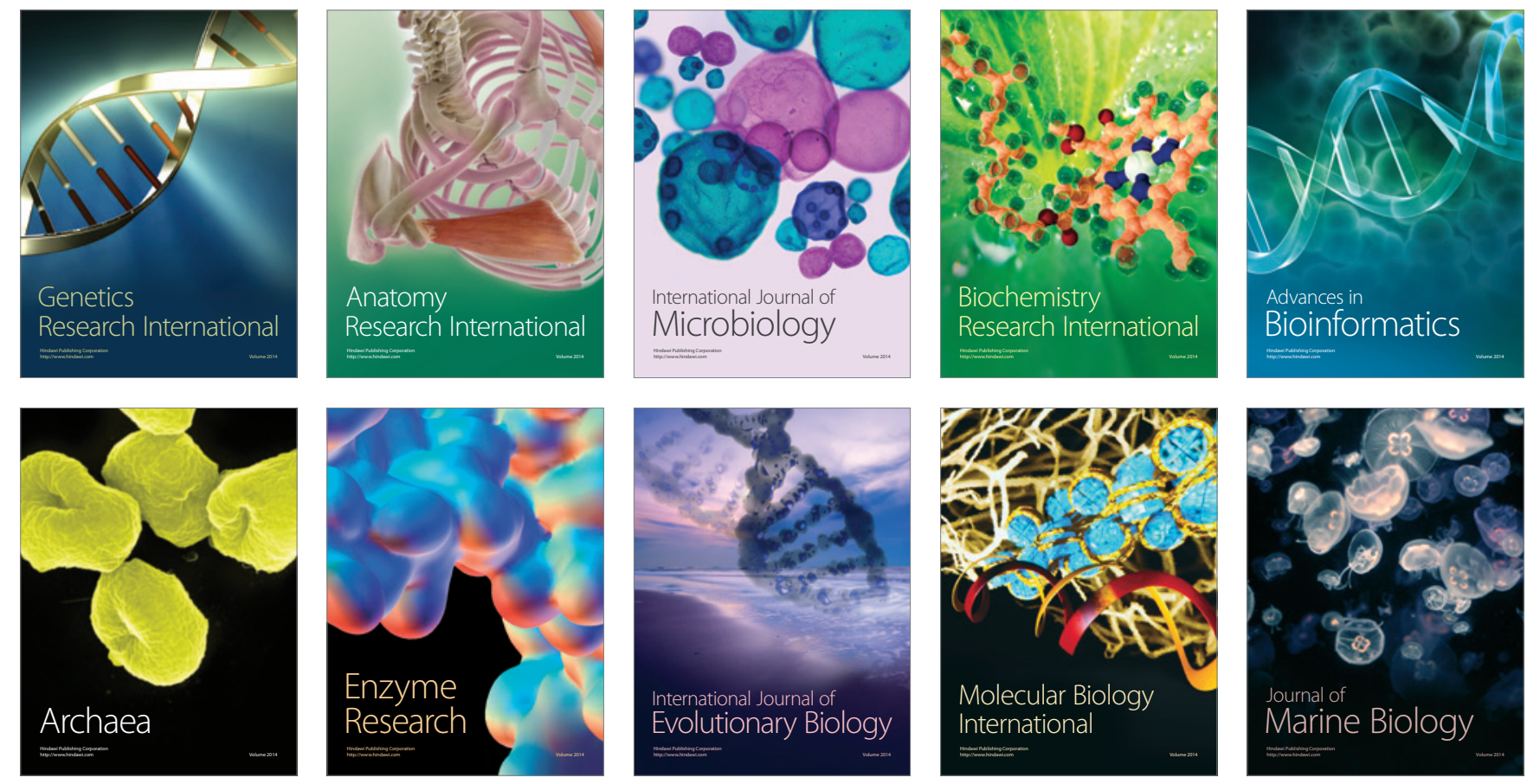